\title{
ORDENAÇÃO DOS ADVÉRBIOS EM -MENTE NA GAZETA DE LISBOA (SÉCULOS XVIII E XIX)
}

\section{POSITION OF ADVERBS ENDING IN -MENTE IN GAZETA DE LISBOA $\left(18^{\text {TH }}\right.$ AND $19^{\text {TH }}$ CENTURIES)}

\section{Susana Fontes ${ }^{*}$}

RESUMO: O início da centúria setecentista ficou marcado pelo surgimento do primeiro periódico oficial português, a Gazeta de Lisboa, em 1715, que se constitui como um marco decisivo na nossa história. Um século volvido, Portugal continua a dispor deste importante órgão de informação, o que nos permitiu constituir um corpus de trabalho com cerca de um milhão de palavras, representativo do estado da língua durante estes dois séculos (XVIII e XIX). Neste artigo, auxiliados por ferramentas de linguística computacional (programas de análise automática de texto), pretendemos analisar os advérbios terminados em -mente presentes no texto e proceder à análise das diferentes posições ocupadas por este grupo de advérbios na frase, para podermos verificar se houve alguma mudança significativa neste percurso e de que forma a predominância de uma determinada posição poderá ter condicionado o próprio valor do advérbio.

PALAVRAS-CHAVE: Gazeta de Lisboa. Séculos XVIII e XIX. Advérbios em -mente. Ordenação. Gramaticalização

\begin{abstract}
:
The beginning of the eighteenth century was marked by the emergence of the first Portuguese official newspaper, Gazeta de Lisboa, in 1715, which is a milestone in our history. A century later, Portugal continues to have this important body of information, allowing us to create a corpus of work with about one million words, representative of the state of the language during these two centuries ( $18^{\text {th }}$ and $19^{\text {th }}$ centuries). In this paper, assisted by computational linguistic tools (automatic text analysis programs), we intend to analyze the adverbs ending in -mente that occur in the text and analyze the different positions occupied by these adverbs in the sentence, so that we can check if there was any significant change and how the predominance of a particular position may have influenced the meaning of the adverb itself.

Keywords: Gazeta de Lisboa. $18^{\text {th }}$ and $19^{\text {th }}$ centuries. Adverbs ending in -mente. Word order. Grammaticalization
\end{abstract}

\footnotetext{
* Doutora em Linguística pela Universidade de Trás-os-Montes e Alto Douro (UTAD) - Vila Real - Portugal. Professora Auxiliar na UTAD.
} 

XIX)

\section{INTRODUÇÃO}

No início da centúria setecentista, nasce a Gazeta de Lisboa, em 10 de agosto de 1715, com o título de Notícias do Estado do Mundo, imitando o modelo autoritário francês, através da emblemática Gazette de Renaudot, muito controlado pelo poder político. Portugal passa, então, a dispor de um órgão de informação, que acompanhou o leitor português durante muito tempo.

Neste artigo, tendo como base o texto jornalístico, constituímos um corpus de trabalho com cerca de um milhão de palavras, para podermos analisar os advérbios terminados em -mente presentes no texto e proceder à análise das diferentes posições ocupadas por este grupo de advérbios na frase, tendo como objetivo verificar se houve alguma mudança significativa neste percurso e de que forma a predominância de uma determinada posição poderá ter condicionado o próprio valor do advérbio.

A Gazeta de Lisboa foi o texto selecionado para a constituição do nosso corpus, por ser um dos periódicos mais importantes e duradouros da nossa história. Neste sentido, optámos por analisar os anos de $1715-1716$ e de $1815^{1}$, o que nos possibilitou a consecução de um estudo sobre a evolução destes advérbios e da posição ocupada pelos mesmos na frase nas centúrias setecentista e oitocentista.

Para levar a cabo este estudo linguístico, utilizámos um recurso informático de processamento automático de texto $(N o o J)$, que nos permitiu obter resultados mais fiáveis e sistemáticos num curto espaço de tempo, no entanto, não nos podemos iludir e pensar que estas ferramentas substituem o trabalho do investigador, uma vez que ele continua a ser o condutor principal da sua investigação e o responsável pela leitura dos resultados facultados pelos programas.

\footnotetext{
${ }^{1}$ A partir deste momento, passaremos a designar de GL-Setecentista e GL-Oitocentista as duas partes do nosso corpus, correspondentes aos anos de 1715-1716 e 1815, respetivamente.
} 


\section{ORDENAÇÃO DOS ADVÉRBIOS EM -MENTE NA GL SETECENTISTA E NA GL OITOCENTISTA}

No nosso corpus, depois de procedermos a um levantamento exaustivo de todos os advérbios em -mente, ou seja, 4621 advérbios, percebemos que no século XVIII estes correspondem a $36,10 \%$ das formas diferentes dos advérbios presentes no texto e, no século XIX, esta percentagem torna-se ainda mais significativa e alcança os $40,82 \%$ das formas diferentes de advérbios.

Depois de analisarmos individualmente todos os advérbios em -mente, tendo em consideração o contexto em que surgem e a sua posição na frase, decidimos dividi-los em três grupos:

1. Advérbios de modo

2. Advérbios de frase

3. Outros (destacam-se claramente aqueles que expressam uma ideia de intensidade/quantificação e de tempo)

Seguidamente, procedemos à análise das diferentes posições ocupadas por este grupo de advérbios na frase, para podermos verificar se houve alguma mudança significativa neste percurso e de que forma a predominância de uma determinada posição poderá condicionar o próprio valor do advérbio. No momento em que procedemos à classificação dos mesmos, sistematizámos todas as posições detetadas, que foram, por sua vez, enquadradas em três grandes grupos, tendo em conta principalmente a existência de advérbios modificadores de verbo e de frase. Num momento inicial, considerámos todos os advérbios em -mente e as suas posições, no entanto, mais tarde, optámos por registar apenas os lugares ocupados pelo maior representante deste grupo, os advérbios de modo, e pelos advérbios de frase.

\subsection{POSIÇÕES RELACIONADAS COM O VERBO}

\section{A) Posições Pré-verbais (AV)}

P1- entre o sujeito e o verbo

“[...] varios mercadores escondidamente embarcavaõ para a Grã Bretanha." (GL, no 14,9 de setembro de 1715, p.68)

P2- antes do verbo (sem sujeito expresso)

"[...] para se embarcarem em huma esquadra de naos de guerra de Dinamarca, que cõmummente chamaõ a flotilha [...]" $\left(G L, \mathrm{n}^{\circ} 5,7\right.$ de setembro de $\left.1715, \mathrm{p} .27\right)$

P3- antes do verbo (com sujeito em posição pós-verbal)

"[...] no anno passado deo principio á paz de que felizmente goza a Europa [...]" (GL, $\mathrm{n}^{\mathrm{o}}$ 99, 28 de abril de 1815: [III]) 
B) Posições Pós-verbais

(VA)

P4- entre o verbo e um complemento

“[...] O nosso Monitor das Duas Sicilias contradiz officialmente os artigos do Jornal dos Debates de 5 de Novembro [...]" (GL, no 12, 14 de janeiro de 1815: [II])

P5- entre um verbo auxiliar e um principal

"[...] a Hespanha ha de certamente conhecer intimamente isto [...]" (GL, $\mathrm{n}^{\mathrm{o}}$ 24, 28 de janeiro de 1815: [IV])

P6- verbo aux $+\mathrm{adv}+$ suj + verb princ.

"Tem certamente estes Sabios espalhado grandes luzes sobre a sciencia administrativa, que fórma a parte mais importante por seus resultados." $\left(G L, \mathrm{n}^{\mathrm{o}} 45,22 \mathrm{de}\right.$ fevereiro de 1815: [III])

P7- entre verbo e sujeito

"Não póde certamente o publico vêr com perfeita indifferença que taes homens affastem sua attenção, dos negocios da nação" ( $G L, \mathrm{n}^{\circ}$ 250, 23 de outubro de 1815: [III])

P8- depois do verbo, sem outros complementos selecionados pelo verbo

"[...] dizendo que o fizeraõ condicionalmente, esperando as suas explicaçoens." (GL, $\mathrm{n}^{\mathrm{o}} 48,28$ de novembro de 1716, p.265)

$\left(\mathrm{VX}^{2} \mathrm{~A}\right)$

P9 - verbo+complemento+advérbio

"Quem precisar de hum Caixeiro para casa de Negocio Estrangeira ou Portugueza, que sabe a lingua Ingleza e Franceza sofrivelmente" (GL, no 111, 12 de maio de 1815: [VIII])

P10 - verbo+sujeito+advérbio

"[...] he Bonaparte certamente hum similhante habitador" (GL, $\mathrm{n}^{\mathrm{o}} 201,26$ de agosto de 1815: [III])

\subsection{POSIÇÕES RELACIONADAS COM A FRASE}

A) Posição Pré-Oracional (AO)

P11- antes do sujeito/início da oração

"Felizmente, a bem da Justiça e das Artes, chegárão os Soberanos alliados a tempo a París" (GL, nº 179, 1 de agosto de 1815: [VII])

B) Posição Pós-Oracional (OA)

P12-final da frase

\footnotetext{
${ }^{2} \mathrm{X}$ é qualquer elemento linguístico que surja entre o verbo e o advérbio.
} 
"[...] o nosso Santissimo Padre Pio VII., que esta tarde aqui dezembarcou felizmente." (GL, no 98, 27 de abril de 1815: [I])

\subsection{OUTRAS POSIÇÕES}

A) Pré ou pós-adverbial (AA)

P13- antes de advérbio

p.214)

"[...] \& se diz que tomarà brevemente mais." (GL, $\mathrm{n}^{\mathrm{o}} 40,3$ de outubro de 1716,

P14- depois de advérbio (mais, menos, tão/tam, muy/mui, muyto)

"[...] por nova ordem de S Santidade, guardado mais cuydadosamente, \& menos abundantemente provido do necessario para o seu sustento [...]" $\left(G L, \mathrm{n}^{\mathrm{o}} 34,22\right.$ de agosto de 1716: 173)

B) Pré ou pós-adjetival/ participial (AAdj/AdjA)

P15- antes de adjetivo/particípio passado

"A Nação Ingleza sobejamente illustrada para que deixe de dar todo o pezo ás circumstancias actuaes [...]" $\left(G L, \mathrm{n}^{\circ} 84,11\right.$ de abril de 1815: [III])

P16- depois de adjetivo/particípio passado

"[...] porém os Friburguezes, apoiados secretamente pelos de Berne, fazem preparativos [...]” (GL, $\mathrm{n}^{\mathrm{o}}$ 64, 16 de março de 1815: [II])

De seguida, de forma a sistematizar os resultados obtidos, apresentamos em tabela a distribuição das posições ocupadas pelos advérbios de frase e advérbios de modo na $G L$ Setecentista e na GL-Oitocentista.

Tabela 1. Distribuição das posições dos advérbios de frase na GL-Setecentista e GL-Oitocentista

\begin{tabular}{|c|c|c|c|c|}
\hline \multicolumn{3}{|c|}{ Posições } & GL-Setecentista $(\%)$ & GL-Oitocentista (\%) \\
\hline \multirow{10}{*}{$\begin{array}{l}\text { Posições } \\
\text { relacionadas } \\
\text { com o verbo }\end{array}$} & \multirow{3}{*}{ Pré-Verbal } & P1 & $15,4 \%$ & $6,3 \%$ \\
\hline & & $\mathrm{P} 2$ & $12,3 \%$ & $13,9 \%$ \\
\hline & & P3 & $1,5 \%$ & $0,3 \%$ \\
\hline & \multirow{7}{*}{ Pós-verbal } & $\mathrm{P} 4$ & $55,4 \%$ & $39,9 \%$ \\
\hline & & P5 & $0 \%$ & $12,7 \%$ \\
\hline & & P6 & $0 \%$ & $0,3 \%$ \\
\hline & & P7 & $0 \%$ & $1,2 \%$ \\
\hline & & $\mathrm{P} 8$ & $3,1 \%$ & $1,8 \%$ \\
\hline & & P9 & $0 \%$ & $0,3 \%$ \\
\hline & & $\mathrm{P} 10$ & $0 \%$ & $2,4 \%$ \\
\hline \multirow{2}{*}{\multicolumn{2}{|c|}{$\begin{array}{l}\text { Posições relacionadas com } \\
\text { a frase }\end{array}$}} & P11 & $1,5 \%$ & $6,9 \%$ \\
\hline & & $\mathrm{P} 12$ & $3,1 \%$ & $3,3 \%$ \\
\hline \multirow{3}{*}{\multicolumn{2}{|c|}{ Outras posições }} & $\mathrm{P} 13$ & $0 \%$ & $0 \%$ \\
\hline & & P14 & $4,6 \%$ & $3,0 \%$ \\
\hline & & $\mathrm{P} 15$ & $3,1 \%$ & $7,6 \%$ \\
\hline
\end{tabular}




\begin{tabular}{|l|l|l|l|}
\hline & P16 & $0 \%$ & $0 \%$ \\
\hline
\end{tabular}

Tabela 2. Distribuição das posições dos advérbios de modo na GL-Setecentista e GL-Oitocentista

\begin{tabular}{|c|c|c|c|c|}
\hline \multicolumn{3}{|c|}{ Posicões } & GL-Setecentista $(\%)$ & GL-Oitocentista $(\%)$ \\
\hline \multirow{10}{*}{$\begin{array}{l}\text { Posições } \\
\text { relacionadas } \\
\text { com o verbo }\end{array}$} & \multirow{3}{*}{ Pré-Verbal } & P1 & $3,3 \%$ & $6,1 \%$ \\
\hline & & P2 & $5,9 \%$ & $6,5 \%$ \\
\hline & & P3 & $0 \%$ & $0 \%$ \\
\hline & \multirow{7}{*}{ Pós-Verbal } & P4 & $52,6 \%$ & $29,9 \%$ \\
\hline & & P5 & $4,9 \%$ & $2,9 \%$ \\
\hline & & P6 & $0 \%$ & $27,5 \%$ \\
\hline & & P7 & $0 \%$ & $4,7 \%$ \\
\hline & & P8 & $14,8 \%$ & $4,2 \%$ \\
\hline & & P9 & $0,6 \%$ & $0,6 \%$ \\
\hline & & P10 & $0,6 \%$ & $2,8 \%$ \\
\hline \multirow{2}{*}{\multicolumn{2}{|c|}{$\begin{array}{l}\text { Posições relacionadas com } \\
\text { a frase }\end{array}$}} & P11 & $1,8 \%$ & $0,7 \%$ \\
\hline & & $\mathrm{P} 12$ & $0,2 \%$ & $4,9 \%$ \\
\hline \multirow{4}{*}{\multicolumn{2}{|c|}{ Outras posições }} & P13 & $0 \%$ & $0,1 \%$ \\
\hline & & P14 & $8,3 \%$ & $2,3 \%$ \\
\hline & & P15 & $6,9 \%$ & $6,0 \%$ \\
\hline & & P16 & $0 \%$ & $0,6 \%$ \\
\hline
\end{tabular}

Antes de concluirmos este trabalho, julgávamos que o número de advérbios de modo terminados em -mente em posição pré-verbal seria superior no século XVIII, seguindo a tendência de outros estudos levados a cabo com corpora dos séculos XVIII e XIX. Referimonos, por exemplo, ao trabalho de Martelotta e Vlček (2006), numa pesquisa sobre estes advérbios em cartas de leitores e de redatores, que revelou uma tendência para esta posição começar a enfraquecer no início do século XIX e desaparecer no final deste século. Lembramos que, numa análise mais abrangente temporalmente, Martelotta, Processy e Santos (2008) haviam já registado que no latim clássico os advérbios ocorriam preferencialmente em posição pré-verbal. Deste modo, Martelotta, nos vários estudos que leva a cabo acerca da ordenação dos advérbios qualitativos do latim ao português atual, regista esta tendência de mudança da posição pré-verbal para a pós-verbal, situando-a principalmente no século XIX.

No nosso corpus, encontramos valores aproximados para a posição pós-verbal nos dois séculos $(72,36 \%$ para VA e 1,22\% para VXA no século XVIII; e 69\% para VA e 3,41\% para VXA), que é claramente a dominante, tal como acontece atualmente. Relativamente à posição pré-verbal, contrariamente ao esperado, registamos que ela apresenta valores mais elevados no século XIX, ainda que estes sejam próximos $(9,15 \%$ para o século XVIII e $12,67 \%$ para o século XIX). Estes valores são o resultado da soma das posições 1 (entre sujeito e verbo) e 2 (antes de verbo, sem sujeito expresso) e verificámos que grande parte destes casos era constituída por orações subordinadas relativas, sendo que este pronome ora ocupava a função sintática de sujeito ora de complemento direto. Constatámos também que, nas orações em que o sujeito é inexistente ou está subentendido, o advérbio tende a ocorrer em posição pré-verbal. No caso das orações relativas, a anteposição é exigida por uma estrutura mais rígida, que é característica deste tipo de oração subordinada em termos de ordenação na frase. Estes resultados associados a orações mais gramaticalizadas apontam para a teoria de Givón (1979), que defende que estas orações são mais conservadoras e, nesse sentido, usam a ordenação mais antiga, que é precisamente a pré-verbal. ${ }^{3}$

\footnotetext{
${ }^{3}$ Martelotta (2006, p.23), no seu trabalho sobre "Ordenação dos advérbios qualitativos em -mente no português escrito no Brasil nos séculos XVIII e XIX", também concluiu que:
} 
Por outro lado, estes valores mostram-nos o predomínio da posição VA em relação à VXA nos dois séculos, o que aponta para a influência do princípio de iconicidade, mais especificamente do subprincípio da proximidade (Givón, 1990), na ordenação dos advérbios na oração. Este princípio assenta numa relação entre a proximidade semântica e sintática, ou seja, os advérbios de modo tendem a ocorrer o mais próximo possível do verbo, uma vez que se referem diretamente a ele, ao modo como se dá uma determinada ação. Nos dois séculos, é evidente que a maioria destes advérbios ocorre o mais próximo possível do seu alvo, quer seja em posição imediatamente anteposta ou posposta.

Relativamente a este subprincípio, Martelotta (2006, p.22) aduz:

[...] entidades que estão próximas funcionalmente, conceptualmente ou cognitivamente ocorrerão próximas no nível da codificação, isto é, temporal e espacialmente. Assim, os advérbios qualitativos, indicadores do modo como se dá a ação verbal, interferindo substancialmente em seu sentido, tendem a ocorrer próximos ao verbo.

Registramos também o fato de que um número significativo destes advérbios no século XVIII (com 8,33\%, que reduz drasticamente para 2,39\% no século XIX) surge intensificado por outro advérbio como tão, mui e outros que expressam quantidade. Por último, estes ocorrem também junto do adjetivo que modificam, com percentagens muito próximas nos dois séculos.

No que diz respeito aos advérbios de frase, seguindo o mesmo subprincípio enunciado, estes não deveriam ocorrer próximos do verbo, uma vez que não se referem a ele, mas sim em posições periféricas, sejam elas a inicial ou final. No entanto, e apesar de se ter verificado um aumento considerável relativamente à anteposição e, no caso específico do século XIX, também verificável para a posição periférica inicial, continuamos a ter como posição dominante a pós-verbal. ${ }^{4}$ É de referir que no século XVIII a posição periférica era praticamente inexistente, facto que se alterou na centúria seguinte.

Este resultado inesperado relativamente ao predomínio da posposição pode estar relacionado com uma trajetória de mudança que ocorreu com alguns destes advérbios, que não surgiram logo como advérbios de frase, mas sim como advérbios de modo, que modificam o verbo e que se posicionam junto dele. Tal como refere Moraes Pinto (2008: 68): "[...] os advérbios qualitativos e modalizadores podem constituir duas faces (ou mais) de uma rede polissêmica, pois certos advérbios modalizadores são qualitativos que se gramaticalizaram."

[...] as ocorrências de qualitativos em -mente em posição pré-verbal tenderão a aparecer em cláusulas com graus maiores de gramaticalização em ambos os séculos analisados. Isso era esperado com base na proposta de Givón (1979), segundo a qual essas cláusulas são mais conservadoras em termos de ordenação, o que significa que elas tendem a preservar a antiga colocação pré-verbal latina.

${ }^{4}$ No estudo levado a cabo por Moraes Pinto $(2008$, p.188) acerca da ordenação dos advérbios na frase, a investigadora encontra também valores elevados para a posição medial nestes séculos e conclui:

$\mathrm{O}$ resultado do levantamento e análise dos advérbios modalizadores demonstrou que esse elemento se coloca, preferencialmente, antes da oração. Porém, foram encontrados dados em posição medial na oração: no português arcaico, havia uma quantidade ínfima (6\%) desses elementos nessa posição (medial). Do século XVII (14\%) ao XIX (60\%), houve um aumento do uso dessa posição, e uma estabilização/ equilíbrio no uso dessa posição no português atual. 
Esta trajetória de mudança por gramaticalização associada a alguns advérbios em mente, já verificada e confirmada em vários trabalhos (Moraes Pinto, 2008 e 2002; Martelotta, 2006; Martelotta e Vlček, 2006), segue-se a um estudo, neste caso sobre o inglês, de Traugott (1995), continuado em Traugott e Dasher (2005), que incide sobre a passagem de alguns advérbios internos à oração a advérbios de frase (sendo que, em alguns casos, estes chegam a marcadores discursivos).

No nosso corpus, há alguns advérbios que apresentam uma trajetória unidirecional de mudança, passando de advérbios internos à oração a advérbios de frase.

\section{ANÁLISE DE ALGUNS CASOS}

Terminamos este estudo sobre os advérbios em -mente na Gazeta setecentista e oitocentista com uma análise individualizada de alguns exemplos desta classe que consideramos interessantes devido ao seu caráter polissémico, por apresentarem alterações de sentido relativamente à base inicial do advérbio ou alterações no que se refere à sua classificação, denotando uma trajetória de mudança.

\section{A) Proximamente}

"Os Confederados de Polonia continuaõ as suas desordens, \& tiverão proximamente novos encontros com os Saxonios[...]" (GL, no 21, 23 de maio de 1716, p.98)

"Os preparativos que se fazem na Igreja de Santo Estevão, Cathedral desta Cidade, demostrão que haverá proximamente hum Te Deum." (GL, no 11, 13 de janeiro de 1815: [II])

"Em consequencia disto, accedeo S. M. á proposição que lhe foi feita por ElRei de Prussia de lhe ceder estas Provincias em troca de outras situadas mais proximamente á Dinamarca." (GL, no 279, 25 de novembro de 1815: [I])

O advérbio "proximamente" apresenta, à partida, um sentido ligado ao espaço, no entanto, verifica-se que assume maioritariamente uma aceção temporal, assemelhando-se a "recentemente", "em breve". No século XIX, à semelhança do que sucede atualmente, predomina o sentido temporal, no entanto temos ainda o advérbio usado com sentido denotativo, mais próximo da sua base adjetival (próximo, perto), como se percebe pelo último exemplo.

\section{B) Justamente}

"Por cartas de Constantinopla de 8 de Setembro se tem a noticia de que o Sultaõ havendo sabido a perda do seu exercito ajuntàra logo o Conselho, \& se fizera divulgar o successo muito differente, dizendo-se só que o Graõ Vizir havia sido justamente morto pelos Janizaros do seu exercito, em razaõ das suas grandes crueldades [...]" (GL, no 49, 5 de dezembro de 1716, p.275)

"Chegou de noyte a Tullibardine, \& a Ardoch lugares distantes, hum 10. milhas, outro 4. de Sterling, \& justamente na mesma distancia de Perth, ficando o Duque de Argile no 
segundo com a retaguarda, \& o General Cadogan com a vanguarda no primeyro." (GL, $\mathrm{n}^{\mathrm{o}} 12$, 21 de março de 1716, p.54)

"Movido o meu Real animo do apreço e gratidão que tão justamente me merecem os eminentes e assignalados serviços com que não poucos dos meus benemeritos Vassallos tem contribuido e contribuem [...]" $\left(G L, \mathrm{n}^{\mathrm{o}} 87,14\right.$ de abril de 1815: [I-II])

"Sem embargo disto, os periodicos de París, fiados sem duvida na falta de reflexão e de bom sizo dos seus leitores, se tem atrevido a fingir alborotos e maquinações forjadas em Hespanha contra este mesmo Soberano, justamente quando toda a nação a huma voz bemdiz a Providencia Divina por the ter dado hum Rei que não conhece outra occupação, outros desejos, nem outro recreio senão procurar o bem de seus vassallos." ( $G L, \mathrm{n}^{\mathrm{o}} 96,25$ de abril de 1815: [II])

"Sua benigna Providencia, que governa sobre nós, e que converte mesmo o mal em bem, permittio que o espirito de rebellião, que em França se conservava occulto, rompesse justamente no momento em que os Soberanos e os Povos, em estado de poderoso apercebimento, se achavão alerta [...]" $\left(G L, \mathrm{n}^{\circ} 186,9\right.$ de agosto de 1815: [II])

No século XVIII, das 5 ocorrências do advérbio justamente, 4 assumem um sentido qualitativo, como é visível no primeiro exemplo apresentado (devido às crueldades cometidas, foi justo que tenha sido assassinado). No caso do segundo exemplo, estamos perante um sentido diferente, assumindo-se como focalizador, que chama a atenção de um determinado constituinte, sinónimo de "precisamente". No século XIX, este uso está mais generalizado, como é claro pelos dois últimos exemplos, reveladores de um trajeto de mudança associado a este advérbio, que passa a funcionar também como um focalizador, ainda que não tenha desaparecido o seu valor qualitativo, visível na primeira frase do século XIX.

\section{C) Finalmente}

"Assegura-se que o Duque Regente quer estabelecer seis tribunaes de Conselho, a saber, de Estado, de Consciẽcia, (de que o Cardeal de Noailhes será Presidente) de Guerra, de Ultramar, de Fazenda, \& de Commercio; \& finalmente este Principe faz particular estudo de contentar o povo." (GL, n 10,12 de outubro de $1715, \mathrm{p} .51)$

"Leo-se ante hontem finalmente, \& o dito Secretario pertende faça a Dieta com a mayor brevidade representaçaõ a S. Mag Imp. do que ElRey seu amo pertende [...]" (GL, $\mathrm{n}^{\mathrm{o}}$ 50,12 de dezembro de 1716, p.282)

"He certo que os exemplos disto erão raros, porém os talentos ainda são mais raros que os exemplos, e em huma sociedade bem constituida, ainda he mais rara a precisão de hum talento superior para governar, do que he raro o mesmo talento. Finalmente, não havia em França lei alguma para excluir cidadão algum de qualquer emprego, e não se havia mister, torno a dizer, senão grandes talentos ou grandes serviços para chegar a todos os cargos." (GL, $\mathrm{n}^{\mathrm{o}} 31,6$ de fevereiro de 1815: [I])

"Conseguio finalmente a Guarda Nacional dispersar esta canalha, e esperamos que os Generaes Alliados não farão responsaveis por taes excessos os pacificos habitantes; os quaes nada tanto desejão como vêr abatida esta amotinadora gentalha, e que se tirem as armas 
daquellas mãos ás quaes nunca se devêrão ter confiado." (GL, $\mathrm{n}^{\circ} 179,1$ de agosto de 1815 : $[\mathrm{V}])$

Estamos, mais uma vez, perante um caso de um advérbio que pode ser classificado como ambíguo, tendo em conta a possibilidade de duas leituras para que apontam os excertos. Normalmente, este advérbio surgia, tal como ainda hoje, para estabelecer uma relação lógica entre as partes do texto, como um conetivo, sinónimo de "por fim, por último". Esta é a leitura que fazemos relativamente aos primeiros exemplos de cada século; contudo, parecenos que o advérbio surge com uma aceção diferente nos segundos excertos, deixando transparecer um juízo de valor do redator, que poderia ser parafraseável pela expressão ("até que enfim").

\section{D) Naturalmente}

"Nesta materia naturalmente formosissima, \& digna naõ só da mais plausivel, \& mais gostosa, mas tambem da mais douta, \& mais generosa curiosidade, teraõ abundantissimamente com que se divertir, os mais doutos curiosos; porque ella neste livro foy ponderada com a novidade de muytas cousas, que por nenhum Escritor foraõ ainda ditas." $\left(G L, \mathrm{n}^{\mathrm{o}} 47,21\right.$ de novembro de 1716, p.264)

"Assim, o numero das plantas descriptas por Mr. de Candolle, na sua obra (que forma 6 volumes em $8 .^{\circ}$ grande), e que crescem naturalmente no sólo da França, sóbe a 6000, isto he, a quasi huma quinta parte dos vegetaes conhecidos em toda a superficie do Globo." $\left(G L, \mathrm{n}^{\mathrm{o}} 281,28\right.$ de novembro de 1815: [III])

"Jámais podem as frazes pomposas de hum advogado eloquente, converter em boa huma causa naturalmente má [...]" $\left(G L, \mathrm{n}^{\circ} 125,30\right.$ de maio de 1815: [IV])

"Recebemos a Gazeta de Madrid de 25 do corrente, a qual nos não dá nenhuma noticia mais moderna de França que as do Paquete ultimo; o que naturalmente era de esperar pela brevidade com que este veio, e que trouxe noticias de París até 15." (GL, $\mathrm{n}^{\mathrm{o}} 179,1$ de agosto de 1815: [VIII])

No século XVIII, temos apenas duas ocorrências deste advérbio, sendo o mesmo usado para modificar o sentido do adjetivo que lhe sucede. No século XIX, para além desta situação, visível no segundo exemplo (causa naturalmente má), verificamos que o advérbio surge também associado ao verbo com um sentido de modo (as plantas crescem de modo natural). Por fim, na última frase, surge-nos afastado desta noção de modo, podendo ser classificado como advérbio de frase modal, que tem como função transmitir a pressuposição do falante relativamente à veracidade da proposição que se segue. A mudança semântica registada neste advérbio deve-se também às alterações da posição que o mesmo ocupa na frase. Atualmente, está generalizado o seu uso como advérbio de frase, sendo rara a sua utilização com sentido de modo.

\section{E) Effectivamente, felizmente}

"Medita-se em huma empreza contra aquelle Reyno, \& se determina obrar taõ effectivamente da nossa parte, que ElRey de Dinamarca possa executar os seus designios 
sobre a Provincia de Schonia, para que sendo por ambas as partes acometidos os Suecos, se resolvão a aceitar a paz, \& possa S. Mag. empregar todas as suas forças contra os infieis." $\left(G L, \mathrm{n}^{\mathrm{o}} 14,4\right.$ de abril de 1716, p.61)

"O Emperador mandou logo escrever a todos os circulos do Imperio, para fazerem prender ao dito Marquez em qualquer parte onde fosse achado; o que effectivamente se executou em Staden [...]" (GL, n ${ }^{\circ} 31,1$ de agosto de 1716, p.158)

"[...] as Ordens que forem mais adequadas para effectivamente impedir que, durante o tempo em que ficar sendo licito o continuar o Trafico de Escravos, segundo as Leis de Portugal, e os tratados subsistentes entre as duas Coroas, se canse qualquer estorvo ás Embarcações Portuguezas, que se dirigirem a fazer o Commercio de Escravos ao Sul da Linha $[\ldots]^{\prime \prime}\left(G L, \mathrm{n}^{\mathrm{o}} 255,28\right.$ de outubro de 1815: [II])

Na primeira ocorrência, effectivamente é um advérbio qualitativo, que está a ser intensificado por outro advérbio ("tão"). Por sua vez, na segunda e terceira ocorrências, ele funciona com o sentido que apresenta atualmente, como um advérbio de frase. No século XIX, não encontramos nenhuma ocorrência deste advérbio expressando modo.

"Todas estas circunstancias cõ a do tumulto do exercito Lituano, a disposição que se vè em ElRey de querer dar gosto aos Vassallos, \& as grandes diligencias do Principe Dalhoruchy, \& do Bispo de Cujavia tem disposto de tal sorte os animos de todos, que se espera concluir felizmente o tratado; promettendo huns, \& outros não se lembrarem mais do passado." (GL, n 39, 26 de setembro de 1716, p.206)

"Pela melhora deste Principe, que salvou felizmente da sua enfermidade de bexigas se cantou o Te Deum, na Igreja de Santo Andre, onde assistio toda a sua familia, o seu Conselho, \& os principaes officiaes da sua Casa, \& de noyte houve huma magnifica cea no seu Palacio, com grandes festejos." (GL, no 42, 17 de novembro de 1716, p.227)

"O direito necessario á conservação da sociedade he sanccionado pela Divindade, que tudo ordenou para que os homens vivessem pacifica e felizmente [...]" (GL, $\mathrm{n}^{\mathrm{o}} 50,28 \mathrm{de}$ fevereiro de 1815: [III])

"Felizmente, a bem da Justiça e das Artes, chegárão os Soberanos alliados a tempo a París" (GL, no 179, 1 de agosto de 1815: [VII])

Nos primeiros exemplos de cada século, temos uma aceção do advérbio como qualitativo, que pode ser parafraseável por "de modo feliz, satisfatório, com eficácia", sentido este que já não encontramos no português atual. Se, no século XVIII, é este o sentido que predomina, no século XIX é claro o percurso de mudança percorrido pelo advérbio, que começa a perder esta característica semântica e se aproxima do sentido que atualmente apresenta, enquanto advérbio de frase que é usado para expressar a opinião do falante em relação ao que é dito: neste caso, exprime um estado de felicidade do redator, que aprecia o facto de eles terem chegado a tempo.

Esta alteração é acompanhada de uma mudança na posição ocupada pelo advérbio, que passa de uma posição interna na oração, próxima do verbo, para uma posição mais periférica, no caso da última frase, início da oração.

Deste modo, é notória a evolução histórica presente nestes advérbios que tiveram os seus valores alterados, passando de advérbios com sentido de modo, localizados normalmente 
perto do verbo que modificam, a advérbios de frase, usados para expressar o posicionamento do falante/escritor relativamente ao que é dito na proposição. ${ }^{5}$

\section{CONSIDERAÇÕES FINAIS}

Em síntese, através destes exemplos ficou claro que alguns advérbios terminados em -mente são polissémicos e alguns deles percorrem uma trajetória unidirecional de mudança por gramaticalização, sendo que ao longo do tempo perdem as características semânticas de itens lexicais e acabam por assumir valores mais abstratos, com funções mais pragmáticas. Na linha dos advérbios estudados por Traugott (1995), verificamos que eles percorrem um trajeto de advérbios internos à oração a advérbios sentenciais. Esta mudança semântica é, muitas vezes, acompanhada de uma mudança na posição que ocupam na frase, como ficou também demonstrado. Desta forma, percebe-se que a posição dominante no nosso corpus tenha sido a pós-verbal, ainda que se tenha verificado um aumento da posição periférica inicial no texto do século XIX, posição praticamente inexistente no século XVIII.

\section{REFERÊNCIAS}

FONTES, Susana (2013). Gazeta de Lisboa (1715-1716 e 1815): Estudo InformáticoLinguístico. Vila Real: Centro de Estudos em Letras / UTAD.

GAZETA DE LISBOA (1715). Lisboa: Na Officina de Pascoal da Silva.

GAZETA DE LISBOA (1716). Lisboa: Na Officina de Pascoal da Silva.

GAZETA DE LISBOA (1815). Lisboa: Na Impressão Regia.

GIVÓN, Talmy (1990). Syntax: a functional-typological introduction. Amsterdam: John Benjamins.

GIVÓN, Talmy (1979). On understanding grammar. New York/San Francisco/London: Academic Press.

MARTELOTTA, Mário E. (2006). Ordenação dos advérbios qualitativos em -mente no português escrito no Brasil nos séculos XVIII e XIX. In: Gragoatá. no $21.2^{\circ}$ semestre. Rio de Janeiro: UFRJ. 11-26. Disponível em http://pt.scribd.com/doc/53034137/gragoata21web-1 (consultado em 7 de fevereiro de 2014).

MARTELOTTA, Mário, e Processy, Wendel, e Santos, Monique (2008). A ordenação de advérbios no latim Clássico e no latim medieval. Cadernos de Letras da UFF - Dossiê: Patrimônio cultural e latinidade. $\mathrm{n}^{\circ} 35$. Rio de Janeiro. 49-59. Disponível em http://www.uff.br/cadernosdeletrasuff/35/artigo3.pdf (consultado em 20 de março de 2014).

\footnotetext{
${ }^{5}$ Moraes Pinto (2008, p.99), na sua análise diacrónica, na qual descreve o comportamento dos advérbios qualitativos e modalizadores em - mente, dá conta deste fenómeno: "Observou-se que alguns advérbios em mente seguem uma trajetória unidirecional de mudança (qualitativo > modalizador), nos moldes dos advérbios estudados por Traugott (1995), passando de advérbios internos à cláusula a advérbios sentenciais."
} 
MARTELOTTA, Mário, e Vlček, Nathalie (2006). Advérbios qualitativos em -mente em cartas de jornais do século XIX. Lingüística: Revista do Programa de Pós-Graduação em Lingüística da Universidade Federal do Rio de Janeiro. Rio de Janeiro. 5-21. Disponível em http://www.letras.ufrj.br/poslinguistica/revista_linguistica/revista_linguistica_v2_n1.pdf (consultado em 13 de maio de 2012).

MORAES PINTO, Deise Cristina (2008). Gramaticalização e ordenação nos advérbios qualitativos e modalizadores em -mente. Tese de Doutoramento, Universidade Federal do Rio de Janeiro, Rio de Janeiro. Disponível em

http://www.discursoegramatica.letras.ufrj.br/download/tese_doutorado_deise.pdf (consultado em 10 de março de 2014).

. Os advérbios qualitativos e modalizadores em -mente e sua ordenação: uma abordagem diacrônica. Dissertação de Mestrado em Letras, Universidade Federal do Rio de Janeiro, Rio de Janeiro, 2000.

TRAUGOTT, Elizabeth Closs, e Heine, Bernd. (eds.) (1991). Approaches to grammaticalization. Volume I. Amsterdan / Philadelphia: John Benjamins Company.

TRAUGOTT, Elizabeth-Closs (1995). The role of the development of discourse markers in a theory of grammaticalization. Paper presented at the $12^{\text {th }}$ International Conference on Historical Linguistics. Disponível em http://www.stanford.edu/ traugott/papers/discourse.pdf (consultado em 19 de maio de 2014).

TRAUGOTT, Elizabeth-Closs, e Dasher, Richard B. (2005). Regularity in semantic change. Cambridge: Cambridge University Press.

Recebido em: 09 de julho de 2015.

Aceito em: 31 de julho de 2015. 